\title{
ARM
}

CLIMATE RESEARCH FACILITY

\section{Surface Energy Balance System HANDBOOK}

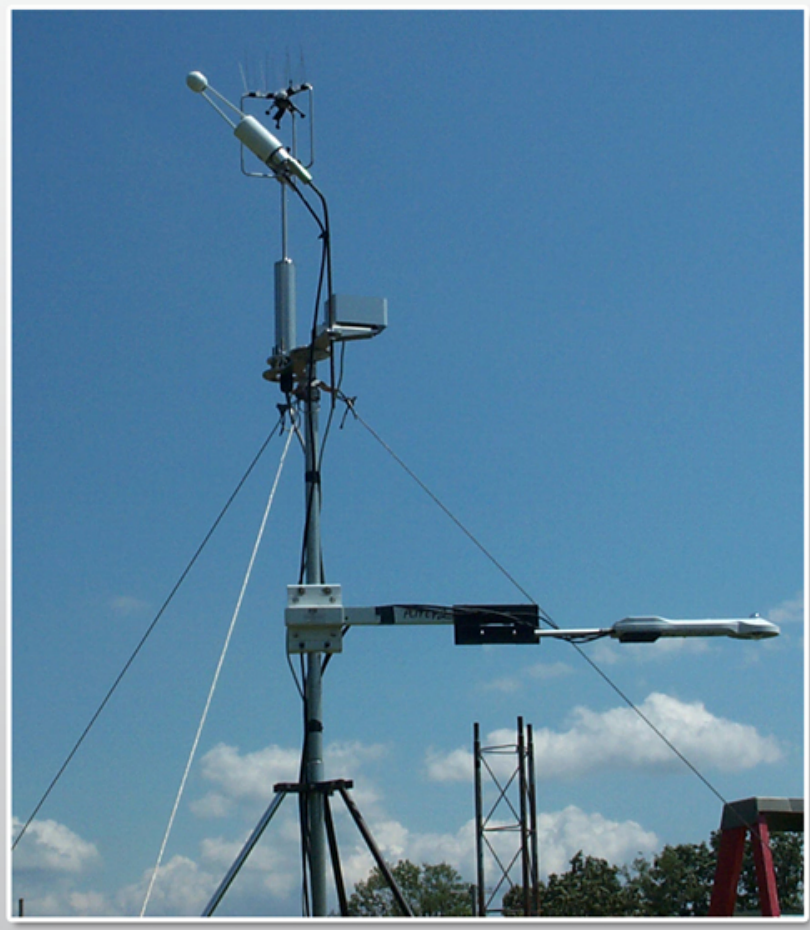

February 2011 


\section{DISCLAIMER}

This report was prepared as an account of work sponsored by the U.S. Government. Neither the United States nor any agency thereof, nor any of their employees, makes any warranty, express or implied, or assumes any legal liability or responsibility for the accuracy, completeness, or usefulness of any information, apparatus, product, or process disclosed, or represents that its use would not infringe privately owned rights. Reference herein to any specific commercial product, process, or service by trade name, trademark, manufacturer, or otherwise, does not necessarily constitute or imply its endorsement, recommendation, or favoring by the U.S. Government or any agency thereof. The views and opinions of authors expressed herein do not necessarily state or reflect those of the U.S. Government or any agency thereof. 


\section{Surface Energy Balance System (SEBS) Handbook}

DR Cook

February 2011

Work supported by the U.S. Department of Energy,

Office of Science, Office of Biological and Environmental Research 


\section{Contents}

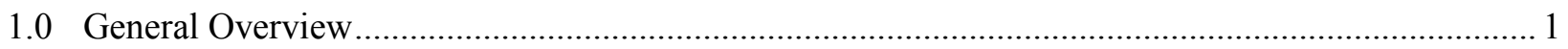

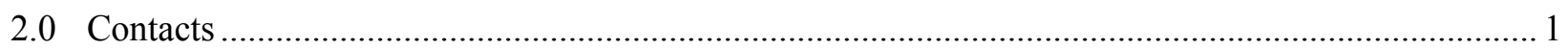

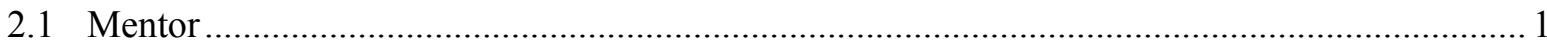

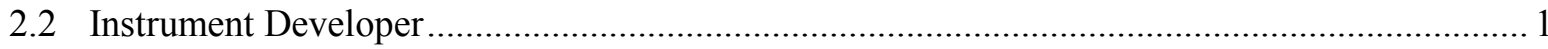

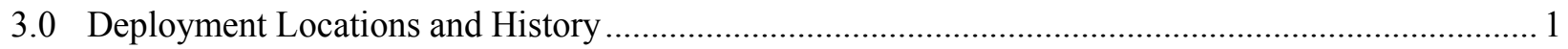

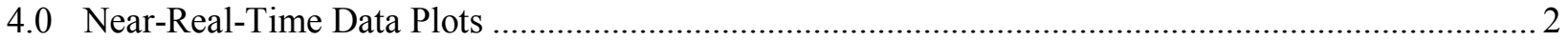

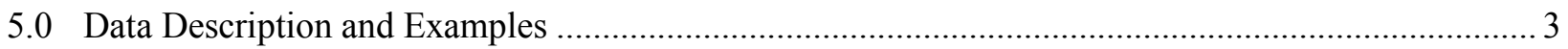

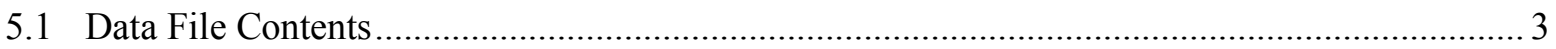

5.1.1 Primary Variables and Expected Uncertainty ............................................................. 3

5.1 .2 Secondary / Underlying Variables ........................................................................... 3

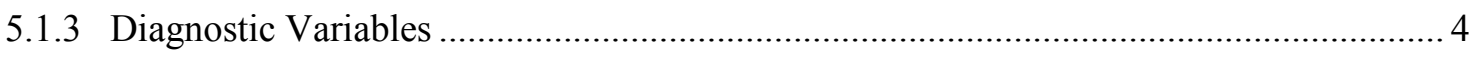

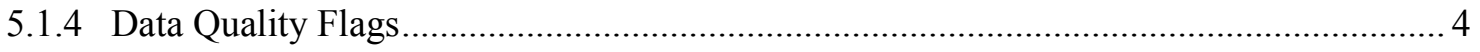

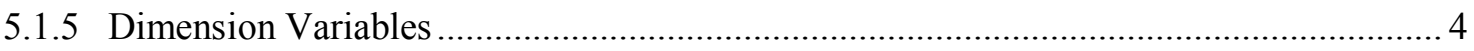

5.2 Annotated Examples ................................................................................................. 5

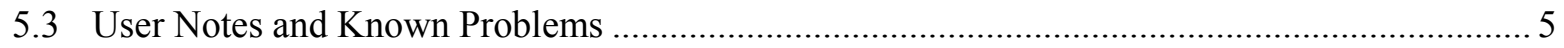

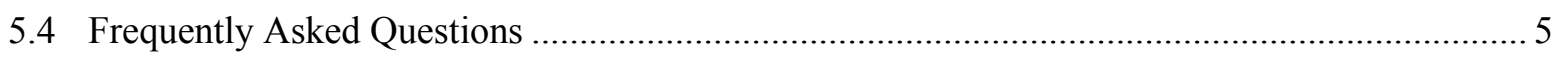

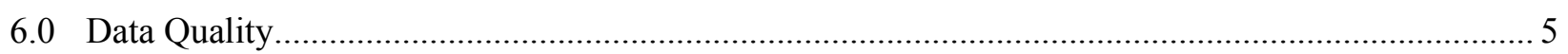

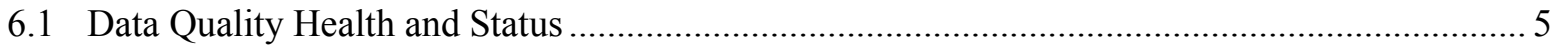

6.2 Data Reviews by Instrument Mentor.................................................................................... 5

6.3 Data Assessments by Site Scientist/Data Quality Office ..................................................... 6

6.4 Value-Added Products and Quality Measurement Experiments................................................. 7

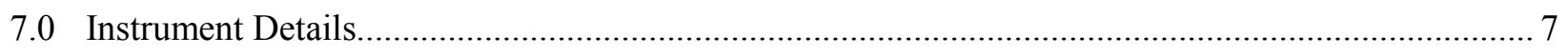

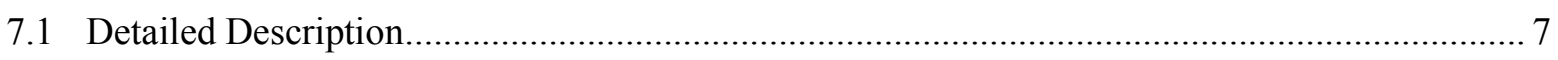

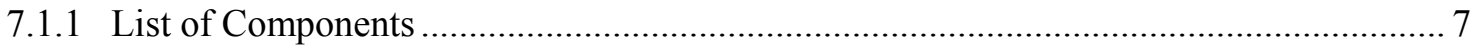

7.1.2 System Configuration and Measurement Methods .................................................... 8

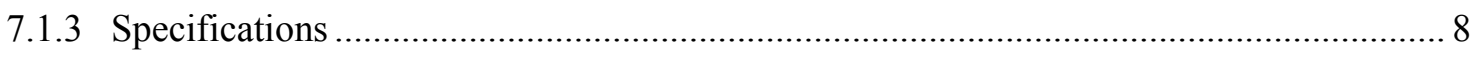

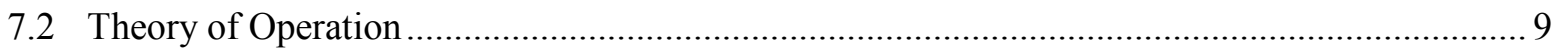

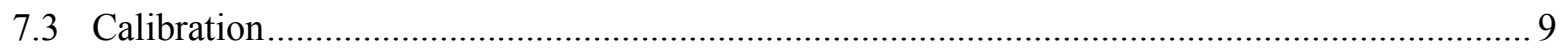

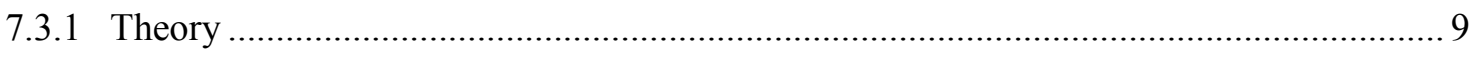

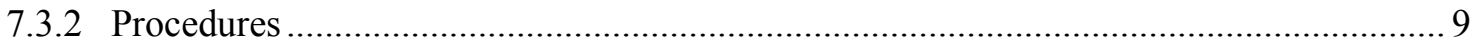

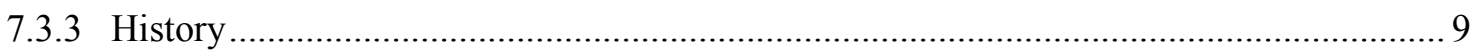

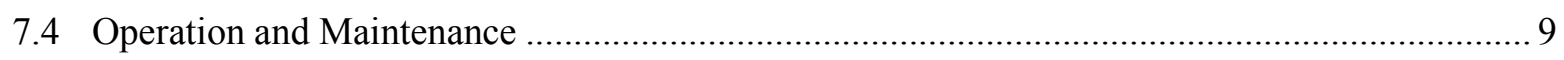

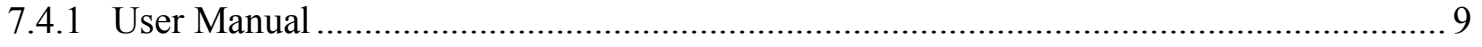

7.4.2 Routine and Corrective Maintenance Documentation ............................................... 9

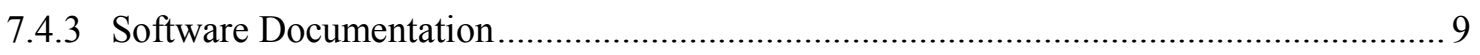

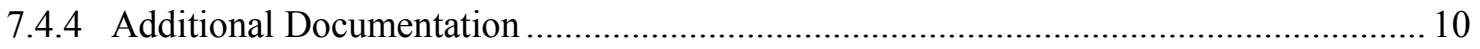




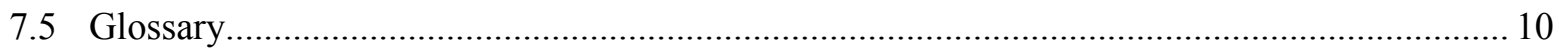

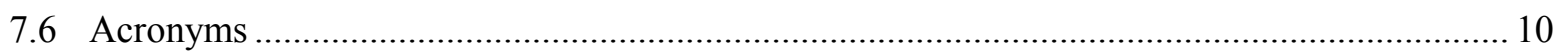

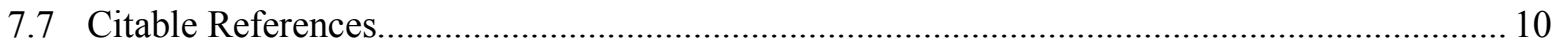

\section{Figures}

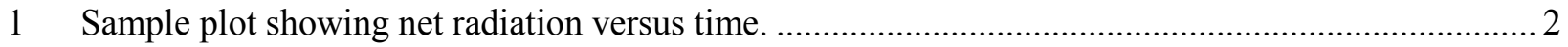

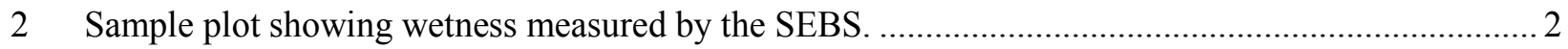

\section{Tables}

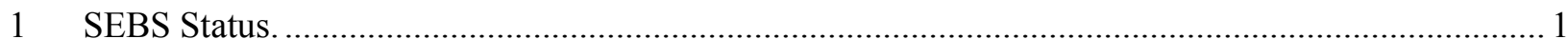




\subsection{General Overview}

A Surface Energy Balance System (SEBS) has been installed collocated with each deployed ECOR system at the Southern Great Plains (SGP), North Slope of Alaska (NSA), Tropical Western Pacific (TWP), ARM Mobile Facility 1 (AMF1), and ARM Mobile Facility 2 (AMF2). The surface energy balance system consists of upwelling and downwelling solar and infrared radiometers within one net radiometer, a wetness sensor, and soil measurements. The SEBS measurements allow the comparison of ECOR sensible and latent heat fluxes with the energy balance determined from the SEBS and provide information on wetting of the sensors for data quality purposes.

\subsection{Contacts}

\subsection{Mentor}

David R. Cook

Environmental Research Division

Argonne National Laboratory, Bldg. 203

Argonne, Illinois 60439

Phone: 630-252-5840

Fax: 630-252-2959

drcook@anl.gov

\subsection{Instrument Developer}

David R. Cook

Environmental Research Division

Argonne National Laboratory, Bldg. 203

Argonne, Illinois 60439

Phone: 630-252-5840

Fax: 630-252-2959

drcook@anl.gov

\subsection{Deployment Locations and History}

Table 1. SEBS Status.

\begin{tabular}{|c|c|c|c|}
\hline Facility & Location & Date Installed & Status \\
\hline SGP/EF6 & Towanda, KS & & Awaiting installation \\
\hline SGP/EF10 & Tyro, KS & & Awaiting installation \\
\hline SGP/EF14 & Lamont, OK & $10 / 18 / 2010$ & Operational \\
\hline SGP/EF16 & Vici, OK & & Awaiting installation \\
\hline SGP/EF21 & Okmulgee, OK & $10 / 20 / 2010$ & Operational \\
\hline
\end{tabular}




\begin{tabular}{|c|c|c|c|}
\hline Facility & Location & Date Installed & Status \\
\hline AMF1 & Various & $1 / 2 / 2011$ & Operational \\
\hline AMF2 & Various & $11 / 1 / 2010$ & Operational \\
\hline TWP/E1 & East Arm & $8 / 11 / 2010$ & Operational \\
\hline TWP/E2 & Beatrice Hill & $8 / 13 / 2010$ & Operational \\
\hline TWP/E3 & Berrimah & Currently at CF & Operational \\
\hline NSA/E1 & Barrow & & Awaiting installation \\
\hline NSA/E2 & Point Barrow & & Awaiting installation \\
\hline
\end{tabular}

\subsection{Near-Real-Time Data Plots}

To view near-real-time plots of SEBS data, visit the NCVweb page at http://dq.arm.gov/ncvweb/ncvweb.cgi or DQ HandS page at http://dq.arm.gov/cgi-bin/dqmenu.

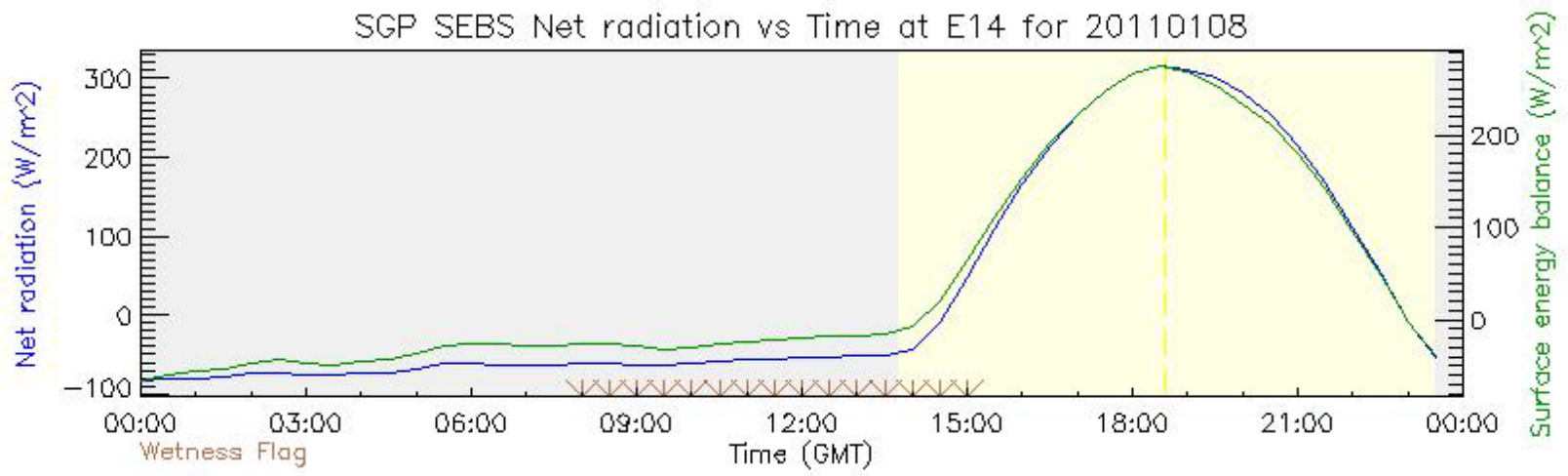

Figure 1. Sample plot showing net radiation versus time.

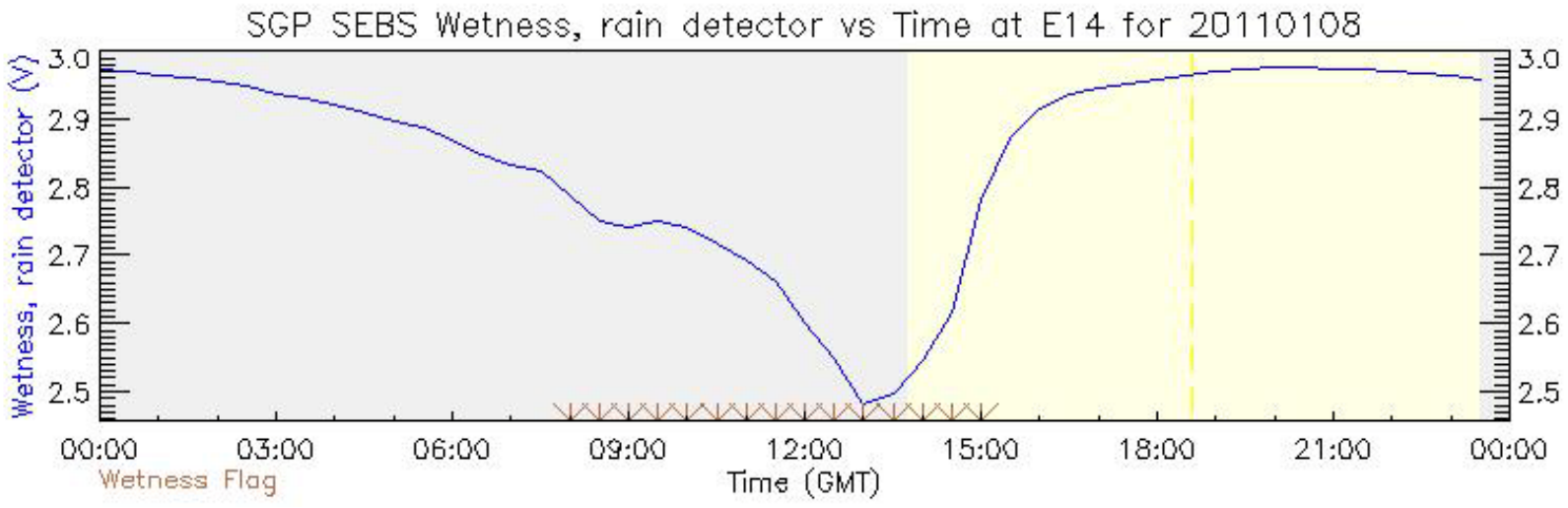

Figure 2. Sample plot showing wetness measured by the SEBS. 


\subsection{Data Description and Examples}

\subsection{Data File Contents}

\subsubsection{Primary Variables and Expected Uncertainty}

30 minutes:

surface_energy_balance: 5\% uncertainty

surface_soil_heat_flux_avg: 10\% uncertainty

net-radiation: $5 \%$ uncertainty

wetness: $5 \%$ uncertainty

\subsubsection{Definition of Uncertainty}

We define uncertainty as the range of probable maximum deviation of a measured value from the true value within a $95 \%$ confidence interval. Given a bias (mean) error $B$ and uncorrelated random errors characterized by a variance $\sigma^{2}$, the root-mean-square error (RMSE) is defined as the vector sum of these,

$$
\operatorname{RMSE}=\left(B^{2}+\sigma^{2}\right)^{1 / 2}
$$

( $B$ may be generalized to be the sum of the various contributors to the bias and $\sigma^{2}$ the sum of the variances of the contributors to the random errors). To determine the $95 \%$ confidence interval we use the Student's $t$ distribution: $t_{\mathrm{n} ; 0.025} \approx 2$, assuming the RMSE was computed for a reasonably large ensemble. Then the uncertainty is calculated as twice the RMSE.

\subsubsection{Secondary / Underlying Variables}

30 minutes:

time_offset

time

down_short_hemisp

up_short_hemisp

down_long

up_long

surface_soil_heat_flux_1

surface_soil_heat_flux_2

surface_soil_heat_flux_3

soil_moisture_1

soil_moisture_2

soil_moisture_3

soil_temp_1

soil_temp_2

soil_temp_3

soil_heat_flow_1 


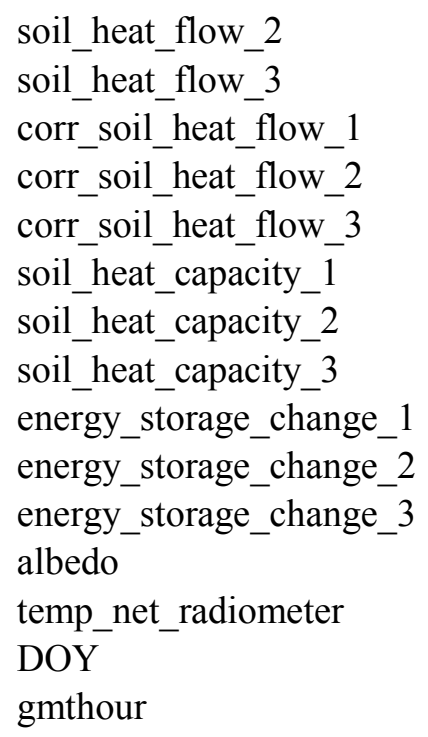

\subsubsection{Diagnostic Variables}

battery_voltage

\subsubsection{Data Quality Flags}

The b1 data file contains basic data-quality flags for most important variables; the flags indicate the variable status (bit values), as follows:

- $0 \mathrm{x} 0=$ value is within the specified range

- $0 \mathrm{x} 1=$ value is equal to "missing_value"

- $0 \mathrm{x} 2$ = value is less than "valid_min"

- $0 x 4=$ value is greater than "valid_max"

- $0 \mathrm{x} 8$ = value failed the "valid_delta" check.

\subsubsection{Dimension Variables}

The global attributes section of the netCDF data file contains geographic coordinates (location) of the SEBS system and the altitude of the ground where the instrument is deployed; the "sensor location" parameter refers to the height of the instrument above the ground. The time variables denote the end of the 30-minute measuring period.

The sign convention for radiometer, net radiation, change of energy storage, and soil heat flux measurements is: positive towards the soil surface and negative away from the surface.

The net radiometer is pointed due south. 


\subsection{Annotated Examples}

Not available at this time.

\subsection{User Notes and Known Problems}

The upwelling and downwelling solar radiation measurements often exhibit small negative values at night; these values are not physically real.

\subsection{Frequently Asked Questions}

Where do I get more information about SEBS systems?

Contact the instrument mentor at drcook@anl.gov.

\subsection{Data Quality}

\subsection{Data Quality Health and Status}

The following links go to current data quality health and status results.

- DQ HandS (http://dq.arm.gov/cgi-bin/dqmenu)

- NCVweb for interactive data plotting (http://dq.arm.gov/ncvweb/ncvweb.cgi)

The tables and graphs at these sites are used by ARM's data quality analysts, instrument mentors, and site scientists to monitor and diagnose data quality.

\subsection{Data Reviews by Instrument Mentor}

- Visual QC frequency: Daily to weekly

- QC delay: Typically 1-3 days

- QC type: Instrument mentor routinely views graphic displays that include plots (day courses) of all calculated quantities and comparison plots (time series or scatter plots) of relevant parameters with data from collocated ECOR, SEBS, EBBR (CF only), and Surface Meteorological Stations (MET, formerly called Surface Meteorological Observing Station (SMOS)) (Cook et al. 2006).

Monthly reviews of the SEBS data are prepared by the mentor and submitted to the Instrument Mentor Monthly Summary (IMMS) report database; these reports are available at "Related Documents" on the SEBS web page.

Data Quality Reports (DQRs) are not written for missing data or for situations when QC flags clearly show that the data are incorrect (this is true for most of the conditions listed below). DQRs are written for periods when data are incorrect, when the situation is not represented by QC flags in the data, and it is not obvious that the data should have been flagged as incorrect. 


\subsection{Data Assessments by Site Scientist/Data Quality Office}

The following guidance has been provided by the SEBS mentor for use by the Data Quality Office in preparing their weekly assessment report for the SEBS systems.

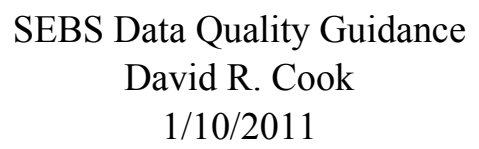

Introduction: The best way to tell someone what to look for in assessing the SEBS data is to describe conditions that reflect correct and incorrect data. For the most part, the QC checks provide adequate guidance. However, there are conditions for which the QC flags may not provide the needed guidance to be able to interpret the correctness of the data. Therefore, please use the information below as further guidance.

Primary Measurements: surface_energy_balance, surface_soil_heat_flux_avg, and net radiation are calculated quantities, whereas wetness is a direct measurement. The $\bar{Q} \mathrm{C}$ limits set in the ingest are appropriate for the measurements (primary and otherwise), although there are times when legitimate values fall outside the QC limits (particularly for upwelling and downwelling solar radiation).

Nuisance QC Flags: The upwelling and downwelling minimum solar radiation flags are frequently tripped at night, exhibiting small negative values that are not physically real; these are instrument offsets.

Comparison of Data at Adjacent SEBS Sites: Only some measurements can be favorably compared with those at adjacent sites, keeping in mind that climate conditions from one side of the ARM site to another can differ sharply. Particular caution must be used in making comparisons between two adjacent sites when they see different vegetation surfaces (Cook et al. 2006). The upwelling radiometer and surface soil heat flux measurements from two sites may not be similar, unless the ground is snowcovered.

Downwelling radiation and wetness measurements may be comparable, remembering that there are likely to be climatologically driven differences. No other measurements can be reliably compared.

Comparisons cannot be reliably made of the measurements of upwelling radiometer and surface soil heat flux measurements at SGP site E21 (forest) versus other SEBS locations in SGP, because the surface vegetation types are so different; such comparisons are likely to show significant differences.

Comparison of Data with the EBBR: The only collocated EBBR and SEBS are at E13/E14 (SGP Central Facility). Caution must be used in the comparison of the two systems because they see different vegetation surfaces (Cook et al. 2006). The net radiation and surface soil heat flux measurements from the two will probably not be similar, unless the ground is snow-covered.

Comparison of Data with MET Instrumentation: MET systems are collocated with ECOR/SEBS systems at most of the ECOR sites (exceptions are SGP E10 and E16). However, there are no measurements of the two systems that can be directly compared. SEBS net radiometer temperature (the temperature of the body of the net radiometer) is normally expected to be higher than Met temperature; they can be expected to be considerably different, especially under warm weather conditions. 
Comparison of Data with the ECOR: There are no measurements of the two systems that can be directly compared. SEBS net radiometer temperature (the temperature of the body of the net radiometer) is normally expected to be higher than ECOR sonic temperature, but may be lower than the LI-7500 $\mathrm{CO} 2 / \mathrm{H} 2 \mathrm{O}$ analyzer temperature; they can be expected to be considerably different under warm weather conditions, especially.

Common Conditions Reflecting Incorrect Data: Upwelling and downwelling solar radiation measurements normally exhibit negative offsets, which do not correspond with physical reality. Measurements exceeding maximum qc values or less than minimum qc values can generally be interpreted as incorrect. Measurements that do not change at all over several hours (particularly if flatlined) may not be correct. The following sources of information can be helpful in determining the value of the SEBS data.

1. See the qc flags in the SEBS data.

2. IMMS Reports at http://www.db.arm.gov/IMMS/.

Conditions that commonly cause the SEBS downwelling radiation measurements to be incorrect include:

- Periods of precipitation, fog, and dew (frost). This is caused by water lying on the upper domes of the net radiometer, thereby obstructing the passage of shortwave and longwave radiation (very light precipitation may have little or no effect). I do not write DQRs or indicate time periods in the monthly report for this wetting condition. The data user should look at the SEBS wetness measurement, the collocated or nearby MET/SMOS rain gauges, or the DQ HandS ECOR plots to determine times of precipitation and dew/frost. You can assume that offscale or spiked readings in the nighttime hours before dawn are normally caused by dew or frost on the upper net radiometer domes.

- Large spikes (positive and negative) in surface_energy_balance and surface_soil_heat_flux_avg can occur when precipitation is heavy. The temperature of the water flowing into the soil from the soil surface (particularly during cold front passages), plus the effects of water/ice/snow on the net radiometer domes can cause such spikes.

\subsection{Value-Added Products and Quality Measurement Experiments}

SEBS data is included in the ECOR VAP. The VAP will perform corrections of ECOR fluxes for WPL buoyancy effects (Webb et al.1980), sensor separation and frequency attenuation effects, outlier removal using the SEBS wetness measurement, and integrate SEBS net radiation and surface soil measurements.

\subsection{Instrument Details}

\subsection{Detailed Description}

\subsubsection{List of Components}

Net Radiometer: CNR4/CNF4 by Kipp \& Zonen

(http://www.kippzonen.com/?product/85182/CNR+4.aspx) 
Spectral range: 300 to 2800 (shortwave) $\mathrm{nm}$

Spectral range: 4500 to 42000 (longwave) $\mathrm{nm}$

Sensitivity: 5 to $20 \mu \mathrm{V} / \mathrm{W} / \mathrm{m}^{2}$

Temperature dependence of sensitivity $\left(-10^{\circ} \mathrm{C}\right.$ to $\left.+40{ }^{\circ} \mathrm{C}\right):<4 \%$

Response time: $<18 \mathrm{~s}$

Non-linearity: $<1 \%$

Operating temperature: -40 to $80{ }^{\circ} \mathrm{C}$

International standards (WMO): Good Quality WMO

Ventilation power: $10 \mathrm{~W}$

Wetness: DRD11A Rain Detector by Vaisala, Inc.

(http://www.vaisala.com/en/products/rainandprecipitationsensors/Pages/DRD11A.aspx)

Range: 1 to 3 V DC (3 V dry, $1 \mathrm{~V}$ wet)

Soil Heat Flow: HFT-3 by Radiation and Energy Balance Systems, Inc.

Range: +/- $10 \mathrm{mV}$

Soil Moisture: SMP1 by Radiation and Energy Balance Systems, Inc.

capacitive sensor measuring resistance ratio

Soil Temperature: STP-1 by Radiation and Energy Balance Systems, Inc.

100 ohm PRTD

Data Logger: CR1000 by Campbell Scientific, Inc.

Multiplexers (2): AM16/32B by Campbell Scientific, Inc.

\subsubsection{System Configuration and Measurement Methods}

In a typical arrangement, the ECOR/SEBS system is placed on the north side of a crop field; the net radiometer is attached to the end of the ECOR boom, beneath the mount that holds the sonic and $\mathrm{CO} 2 / \mathrm{H} 2 \mathrm{O}$ sensor heads, at approximately $3 \mathrm{~m}$ above ground level (15 m height at SGP site EF21 forest). The wetness sensor is mounted on the top of the boom, midway between the two ends of the boom. The soil sensors are buried in the soil under the sonic and $\mathrm{CO} 2 / \mathrm{H} 2 \mathrm{O}$ sensor heads. The data logging equipment is installed in an enclosure attached to the ECOR tower.

30-min average measurements are stored within the CR1000 datalogger and retrieved by the ECOR computer. The SEBS timestamp is the end of the half hour. The CR1000 data files are transferred to the site data system for ingest (conversion into the netCDF format and incorporation of QC flags) and shipment to the ARM Data Archive.

\subsubsection{Specifications}

See instrument specifications in Section 7.1.1. 


\subsection{Theory of Operation}

The surface energy balance is determined from the net radiometer and soil sensor measurements. Upwelling and downwelling solar and infrared radiation measurements are combined to determine net radiation. The net radiometer measurements are adjusted to compensate for the temperature of the net radiometer body. Soil measurements are performed by three sets of soil heat flow ( $5 \mathrm{~cm} \mathrm{depth),} \mathrm{soil}$ temperature ( $0-5 \mathrm{~cm}$ average), and soil moisture (centered at $2.5 \mathrm{~cm})$ probes. Soil heat flow is adjusted for the effect of soil moisture above the soil heat flow plate. The storage of energy in the soil above the soil heat flow plate is determined from the change in soil temperature with time.

Measurements from the three sets of soil probes are combined to give an average soil surface heat flux. Under vegetation canopies (particularly tall vegetation), the soil surface heat flux probably underestimates the heat flux from the top of the canopy. Soil surface heat flux and net radiation are combined to produce an estimate of the surface energy balance.

\subsection{Calibration}

\subsubsection{Theory}

All sensors are factory calibrated. Periodic in situ checks of the net radiometer calibrations are possible, but are not normally needed for years.

\subsubsection{Procedures}

All sensors would be returned to the vendor for factory calibration, if needed.

\subsubsection{History}

Not applicable.

\subsection{Operation and Maintenance}

\subsubsection{User Manual}

No single comprehensive user manual for the SEBS system is available for general use; rather, vendorsupplied documentation on sensors and a collection of procedures prepared by the mentor are provided for internal use by Site Operations.

\subsubsection{Routine and Corrective Maintenance Documentation}

\subsubsection{Software Documentation}

SEBS Preventive Maintenance procedures and reports are stored in the Operations Status System (OSS) and are available to instrument mentors. Please contact the instrument mentor for more information. 


\subsubsection{Additional Documentation}

Not applicable.

\subsection{Glossary}

See the ARM Glossary at http://www.arm.gov/about/glossary.

\subsection{Acronyms}

$\begin{array}{ll}\text { ARM } & \text { Atmospheric Radiation Measurement } \\ \text { DQ } & \text { Data Quality } \\ \text { DQ HandS } & \text { Data Quality Health and Status } \\ \text { DQR } & \text { Data Quality Report } \\ \text { ECOR } & \text { Eddy Correlation Flux Measurement System } \\ \text { EF } & \text { Extended Facility } \\ \text { EFSCO } & \text { EF Surface Conditions Observations } \\ \text { IMMS } & \text { Instrument Mentor Monthly Summaries } \\ \text { IR } & \text { infrared } \\ \text { MET } & \text { Meteorological Instrumentation } \\ \text { NSA } & \text { North Slope of Alaska } \\ \text { QC } & \text { quality control } \\ \text { REBS } & \text { Radiation and Energy Balance Systems, Inc. } \\ \text { RMS } & \text { root mean square } \\ \text { SEBS } & \text { Surface Energy Balance System } \\ \text { SGP } & \text { Southern Great Plains } \\ \text { SMOS } & \text { Surface Meteorological Observing Station } \\ \text { TWP } & \text { Tropical Western Pacific } \\ \text { WPL } & \text { Webb, Pearman, Leuning } \\ & \end{array}$

Also see the ARM Acronyms at http://www.arm.gov/about/acronyms.

\subsection{Citable References}

Cook DR, ML Fischer, and DJ Holdridge. 2006. "Comparison of ECOR, EBBR, and CO2FLX System Fluxes." Presented at the Sixteenth ARM Science Team Meeting, Albuquerque, New Mexico.

Webb EK, GI Pearman, and R Leuning. 1980. "Correction of flux measurements for density effects due to heat and water vapour transfer." Quarterly Journal of the Royal Meteorology Society 106(44): 85-100. 

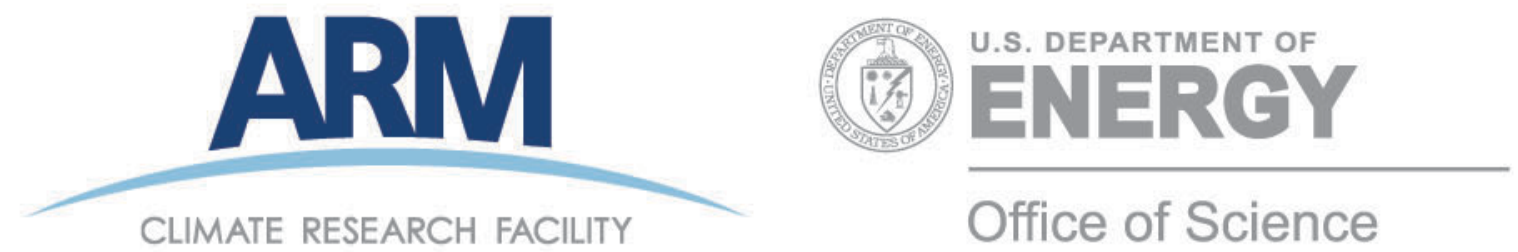
www.arm.gov 